\title{
Nutritional status of preschool children and its associates: A Sri Lankan experience of a fishing community
}

\author{
Chandrasekara Karunamuni Pushpika Sudarshini De Silva ${ }^{1}$, De Silva Hiranthi ${ }^{2}$, \\ Indrapala Waldeniyage Kolitha Prasanna ${ }^{3}$ \\ ${ }^{1}$ Medical Officer, Department of Community Medicine, Faculty of Medicine, University of Ruhuna, Galle, Sri Lanka \\ ${ }^{2}$ Consultant in Community Medicine, Former director- Mental Health, Ministry of Health, Colombo, Sri Lanka \\ ${ }^{3}$ Medical Officer, Base Hospital, Balapitiya, Sri Lanka
}

Email address:

pushpikac@gmail.com (C. K. P. S. De Silva)

\section{To cite this article:}

Chandrasekara Karunamuni Pushpika Sudarshini De Silva, De Silva Hiranthi, Indrapala Waldeniyage Kolitha Prasanna. Nutritional Status of Preschool Children and Its Associates: A Sri Lankan Experience of a Fishing Community. European Journal of Preventive Medicine.

Vol. 3, No. 2-1, 2015, pp. 31-35. doi: 10.11648/j.ejpm.s.2015030201.16

\begin{abstract}
Introduction: Childhood malnutrition remains one of the most challenging global public health problems. To combat this problem, it is essential to reveal the magnitude of malnutrition and underlying socio- cultural factors influencing child feeding and raring. Despite satisfactory income levels, fishing families have low standards of living due to their different life styles and behavioral attitudes which can contribute to poor nutritional status among their children. Methodology: A cross sectional study was conducted among a group of marine fishing families in $\mathrm{MOH}$ area Ambalangoda. Study population consisted of all children (189) aged 1-5 years. Height and weight and nutritional status were assessed. Pre tested interviewer administered questionnaire was used to evaluate the selected socio-demographic and cultural factors of these families affecting the nutritional status. Results: Prevalence of different forms of malnutrition reported was underweight- $31 \%$, stunting- $23 \%$ and wasting- $11.2 \%$. Prevalence of alcoholism was $37.9 \%$ while smoking was $45.5 \%$. Parental level of education, mother's employment status was not significantly related to the nutritional status. Significant association was found between maternal literacy with underweight and wasting while literacy of father with stunting. Father being an alcoholic was significantly related to wasting, stunting and underweight. Father's state of smoking has also being identified as a significant associate of underweight and stunting. Method adopted to dispose excreta of children also found to be significantly associated factor with underweight of their preschool children. Conclusions and recommendations: Parental literacy, father's substance abuse was identified as associated factors for malnutrition in this community and health educational and promotional programmes should be targeted towards these factors using audio visual aids considering the levels of literacy of parents.
\end{abstract}

Keywords: Nutritional Status, Malnutrition, Preschool Children, Fishing Families, Associates

\section{Introduction}

It is an asset of the country for its nation to be nutritionally well balanced and grown healthy, enabling to lead a socially and economically productive life. Malnutrition of infants and preschoolers remains one of the most severe global public health problems (1). It is a silent emergency and invisible crisis. Persistence of malnutrition undetected and without any appropriate interventions shown to be having profound and frightening implications for children, society and the future of the entire mankind. A meta analysis revealed that children of 6 to 60 months of age with mild to moderate malnutrition had 2.2 times higher risk of mortality and 6.8 times higher risk for severely malnourished during the follow up period than their better nourished counterparts (2). In Sri Lanka also has been reported a considerable proportion of underweight $(21.1 \%)$, stunting $(17.3 \%)$ and wasting (14.7\%) prevailing among preschoolers according to the survey conducted by the department of census and statistics.(3)

Of all age groups children below 5 years of age are considered to be nutritionally the most vulnerable. In the first few years of one's life physical and mental growth and development takes place very rapidly relative to the rest of the life. If this increased demand is not met considerable retardation in growth can occur during the early childhood leading to adverse consequences such as morbidity, mortality, 
reduce intellectual performances and late outcomes such as reduce work capacity and productivity (4).

To take appropriate actions to combat the malnutrition, it is essential to reveal the problem of nutrition and its underlying influencing factors, most of the time to be social, economical and cultural factors affecting the child feeding and rearing.

Being an island surrounded by the sea, marine fisheries industry is considered to be an important industry in Sri Lanka accounts to about 441, 707 populations of total fishing households (5). People of fishing communities are distinct from other communities as the fathers are most of the time away from home working hard at the sea while mother being the key figure in the home front. In spite of their satisfactory income levels they have low standards of living due to their different life style and behavioral attitudes (6). According to the Leitan majority of them are alcoholics and smokers (6).

Therefore the present study was conducted to assess the nutritional status and to probe into some selected factors affecting the nutritional status of children of 1-5 years in a fishing community in Sri Lanka.

\section{Materials and Methods}

It was a descriptive cross sectional study carried out in the medical officer of health $(\mathrm{MOH})$ area Ambalangoda, Sri Lanka. It is one of the $7 \mathrm{MOH}$ areas lying along the costal belt of Galle District of Southern Sri Lanka where the marine fishing communities live.

Study population consisted of all children of age 1-5 years living in the $\mathrm{MOH}$ area Ambalangoda whose parents' main source of income was from marine fishing. The total number of children of aged 1- 5 years living in this area was 189 and recruited all of them into the study.

Weight and height/ length were measured using standardized salter and seca weighing scales and height measuring tape and standard height boards. In order to minimize the inter rater variability a proper training was given to the data collectors before the commencement of the survey. The accuracy and reliability of the measurements were ensured by random checking of measurements in the field.

A pretested interviewer administered questionnaire was used to collect information related to factors associated with the nutritional status of the children of 1-5 years. Face, consensual and content validity was asses to ensure the validity of data.

Z-scores were calculated for height-for-age, weight-forheight and weight-for-age. Prevalence of stunting, wasting and underweight was determined using $\mathrm{Z}$ scores less than -2SD of height-for-age, weight-for-height and weight-for-age respectively of the CDC/NCHS (2000) reference standards. There after a number of cross tabulations were carried out and chi square test statistics to identify the association between the selected variables and the nutritional status of the children.

The data was analyzed by using the EPI INFO, EPI NUT and SPSS statistical software.

\section{Results}

The study population comprised of 189 children of 1-5 years. The distribution of the sample according to the age and gender is given in Table 1.

Table 1. Distribution of children according to their age and gender.

\begin{tabular}{llll}
\hline & & Frequency & Percentage\% \\
\hline \multirow{4}{*}{ Age in months } & $13-24$ & 67 & 35.8 \\
& $25-36$ & 43 & 23.0 \\
& $37-48$ & 43 & 23.0 \\
\multirow{4}{*}{ Sex } & $49-60$ & 34 & 18.2 \\
& Male & 92 & 49.2 \\
\hline
\end{tabular}

Nutritional status of the population

When considering the prevalence of different forms of malnutrition in this particular population, $31 \%$ were underweight (having $\mathrm{Z}$ score for weight for age less than $2 \mathrm{SD}$ ), $23 \%$ were stunted ( $Z$ scores for height for age less than -2SD) and $11.2 \%$ were stunted ( $Z$ scores for weight for height less than -2SD).

Table 2. Distribution of children according to the weight for age.

\begin{tabular}{lll}
\hline Weight for age & Frequency & Percentage \\
\hline Underweight & 58 & 31.0 \\
Normal weight & 129 & 69.0 \\
Total & 187 & 100.0 \\
\hline
\end{tabular}

Table 3. Distribution of children according to the height for age.

\begin{tabular}{lll}
\hline Height for age & Frequency & Percentage \\
\hline Stunted & 43 & 23.0 \\
Normal height for age & 144 & 77.0 \\
Total & 187 & 100.0 \\
\hline
\end{tabular}

Table 4. Distribution of children according to the weight for height.

\begin{tabular}{lll}
\hline Weight for height & Frequency & Percentage \\
\hline Wasted & 21 & 11.2 \\
Normal for weight for height & 166 & 88.8 \\
Total & 187 & 100.0 \\
\hline
\end{tabular}

Distribution of the study population according to the selected parental socio demographic characteristics are as follows.

Table 5. Distribution of the study population according to the selected parental socio demographic characteristics.

\begin{tabular}{|c|c|c|c|}
\hline Selected variable & Categories & Frequency & Percentage \\
\hline \multirow{2}{*}{ Employment status of the mother } & Yes & 12 & 6.5 \\
\hline & No & 175 & 93.5 \\
\hline \multirow{3}{*}{ Level of education of mother } & No schooling & 18 & 9.6 \\
\hline & Grade $6-10$ & 126 & 67.4 \\
\hline & $\mathrm{A} / \mathrm{L}$ and above & 21 & 11.2 \\
\hline
\end{tabular}




\begin{tabular}{llll}
\hline Selected variable & Categories & Frequency & Percentage \\
\hline & No schooling & 8 & 4.3 \\
Level of education of father & Grade 1-5 & 79 & 42.2 \\
& Grade 6-10 & 91 & 48.7 \\
& A/L and above & 9 & 4.8 \\
Ability of the mother to read and understand a written document & Can & 155 & 82.9 \\
& Cannot & 32 & 17.1 \\
Ability of the father to read and understand a written document & Can & 27 & 85.6 \\
& Cannot & 153 & 81.8 \\
Number of younger siblings & Non & 33 & 17.6 \\
& 1 & 1 & 0.5 \\
Father's substance abuse & 2 & 71 & 37.9 \\
& Alcohol & 85 & 45.5 \\
Method of disposal of child's excreta & Smoking & 126 & 67.7 \\
Using boiled cooled water for drinking & Correct & 61 & 32.3 \\
\hline
\end{tabular}

Number of cross tabulations were done to elicit the association of the above selected factors with the three

different forms of malnutrition; underweight, stunting and wasting.

Table 6. Association of the selected socio-demographic variables with different under-nutrition indicators.

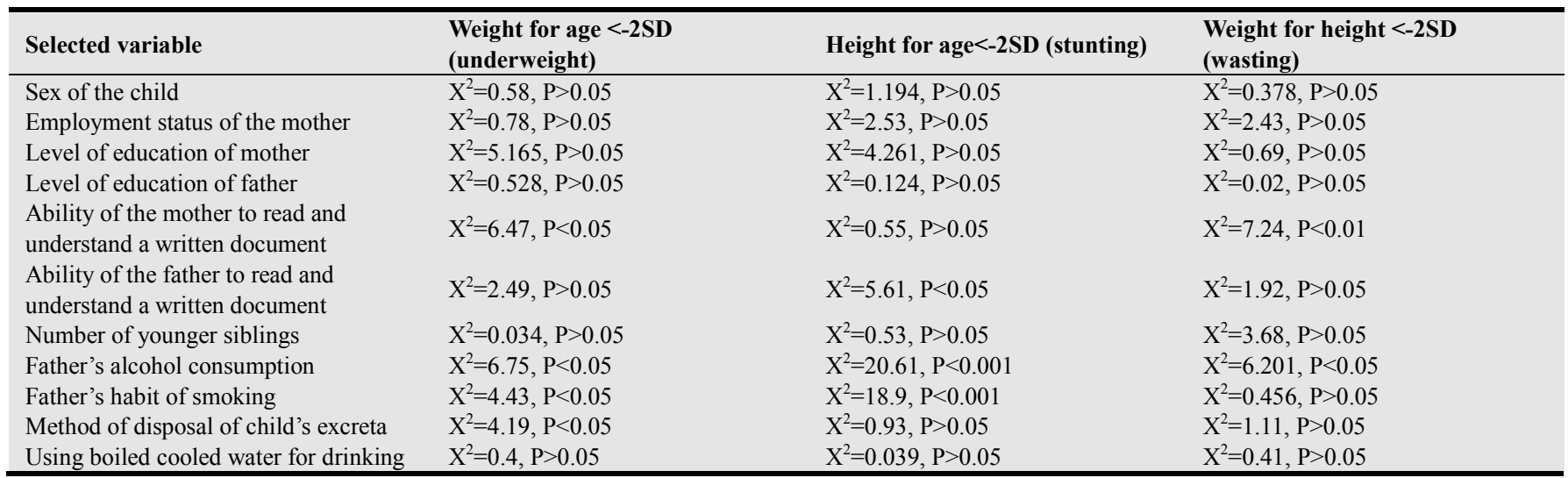

$\mathrm{X}^{2}-$ Chi square value

\section{Discussion}

The prevalence of under nutrition in this particular population was found to be $31 \%$ underweight, $23 \%$ stunting and $11.2 \%$ wasting. According to the demographic and health survey $2006 / 7$ the under nutrition reported as stunting $17.3 \%$, wasting $14.7 \%$ and underweight $21.1 \%$ (3) This indicates that the present study population is having higher proportion of stunting or chronic malnutrition and underweight when compared to the national figures as a whole. In the nutritional country profile published by the Food and Agriculture Organization had shown that presence of interprovincial differences in the nutritional status of preschool children (7). As the underlying determinants of nutritional status vary according to the cultural and other socio economic discrepancies prevailing across the different settings of the country may be the underlying reason for variations of nutritional status across the country.

Individual studies done in two separate locations of the country, at the north end and the south end has revealed that the malnutrition been a health problem of concern (8), (9). A study done in Weeraketiya located in Southern Sri Lanka revealed that $59 \%$ of the children under- 5 years of age had some form of malnutrition. Majority of them were wasted (42.7\%). According to the same study the prevalence of underweight and stunting among these children were $41.2 \%$ and $11.8 \%$, respectively (9). It has been reported in the war affected Jaffna peninsula the problem of malnutrition accounts to about $26 \%$ of the preschool children in the region have been suffering by acute on chronic malnutrition. Among them $15.9 \%$ are from the poor socioeconomic group (8). Hence it is evidenced that the correlation of the socio economic conditions with the state of malnutrition of the children. The same study evident the significant association between socioeconomic status and the status of growth ( $\mathrm{X} 2=25.67, \mathrm{df}=8, \& \mathrm{p}<0.05$ ). The variations in the state of malnutrition of different locations probably are due to the socio economic as well as the cultural and demographic variations across these locations.

According to the present study a significant association was found between the parents' ability to read and understand a written document, father being an alcoholic and a smoker and adoption of incorrect methods for the disposal of child's excreta. 
Among the socio economic determinants of malnutrition of children, level of education of parents especially of mother's proven to play an important role. A study done on children attaining the age of 2 years, living in the University community health project area, Kotte in Sri Lanka mother's level of education was found to be influencing the nutritional status of children (10) Another study done on a group of children living in an urban setting, parental education was found to be influencing the nutrient intake and thereby the higher prevalence of protein energy malnutrition (11). In pace with the above results the present study also revealed a significant association between the parental education and the nutritional status of their preschool aged children.

Level of literacy of an individual is an important factor affecting one's nutritional status. The impact of maternal literacy on the nutritional status of preschool children was studied in India revealed that the children of literate mothers had better anthropometric measures than children of illiterate mothers (12). Findings of the current study also show a significant association between parental illiteracy with the malnutrition status of children, but not with the level of education of the parents.

Relationship of mother's employment status and the nutritional status of children 12- 18 months of age were examined in a study in Nicaragua and revealed a positive association of mother being a working mother and a better nutritional status (13). A contradictory result have been shown in another study where nutrient intake of children of working mothers is significantly lower than that of non working mothers while holding other factors constant (14). This particular study did not show any significant association between the employment status of the mother and the nutritional status of their children which is of different result of the previously done studies.

Environmental sanitation plays an important role in the transmission of enteropathogens and thereby diarrheal diseases. Association of proper disposal of excreta with the malnutrition is plausible as maintenance of hygienic conditions may have reduce the incidence of diarrheal diseases and this in turns affect the nutritional status of the children (15). Another study done in a diarrheal unit in large metropolitan city socio demographic indicators such as unprotected surface water, unhygienic latrine and maternal illiteracy have found to be significantly associated with severe malnutrition in their children (16).

Father's and mother's education, wealth index, source of drinking water of the household, toilet facility, and total number of children ever born to a woman are significantly associated with child malnutrition in Bangladesh (17).

Father's substance abuse is shown here to be having a negative impact on the nutritional status of the children according to the present findings. Father being an alcoholic and a smoker leading to financial instability may be the probable explanation for the above association elicited in the present study. In a survey done in Bangladesh, it has been shown that smoking five cigarettes a day in a household could lead to a monthly dietary deficit of 8000 calories, nearly a quarter of the monthly maintenance of energy requirement of a 12 kilograms weighing child (18) further explains the above association.

\section{Conclusion}

Significant association was found between the parental ability to read and understand a written document, father's substance abuse, adopting correct methods for the disposal of excreta with the state of under nutrition of preschool children in this community.

Health education should be delivered to this particular community using audio visual medias rather than printed materials may improve the nutritional knowledge which in turn will have positive implications on the nutritional status of the children. Health promotional programs aiming at reducing substance abuse, reaching adults as well as school children would be beneficial in improving the nutritional status of the future generations.

\section{References}

[1] De Onis, M. and Hubicht, J.P. 1997,Anthropometric reference data for international use: recommendation from a WHO expert committee, food and nutrition bulletin, 18(2), 179-188

[2] Schroeder, D. J., Brown, K.H. Nutritional status as a predictor of child survival: summarizing the association and quantifying its global impact, Bull World Health Organ. 1994; 72(4): 569579 .

[3] Demographic and Health Survey- 2006/07, Department of Census and Statistics, Colombo, Sri Lanka, Chapter 11 Nutrition of children and women, pp135- 158

[4] Garrows, J.S., Human nutrition dietatics, Chapter 2; 1987, pp $13-15$

[5] Department of census and statistics, Statistical abstract 2001, Chapter 7

[6] Leitan, T. 1995, Women in the fishing industry, Center for society and religion.

[7] Nutrition country profile Sri Lanka, 2010, Nutrition and consumer protection, Food and agriculture organization retrived from http://www.fao.org. Retrieved on 20/9/2014

[8] Elankumaran, C. 2003, Malnutrition in pre-school children of Jaffna Society- A post-exodus statistical perspective proceedings at the 9th International conference on Sri Lanka Studies, 28th - 30th November 2003, Matara, Sri Lanka

[9] Peiris, T.D.R..and D.G.N.G. Wijesinghe, Nutritional Status of under 5 Year-Old Children and its Relationship with Maternal Nutrition Knowledge in Weeraketiya DS division of Sri Lanka, Tropical Agricultural Research, 2010, 21(4): 330 - 339

[10] Rajapaksha, L. and Fernando, D. N. 1987, Sex difference as a risk factor in child malnutrition, Ceylon journal of child health; pp 17-25

[11] Wickramasinghe, N., Gunawardana, D. G., Wickramanayaka, T. M. 1989, Factors influencing the nutritional status of infants and preschool children of the urban poor, Ceylon Journal of Medical Sciences; 32(1): 929-941 
[12] Arya, A. Devi, R. 1991, Influence of maternal literacy on the nutritional status of preschool children; Indian Journal of Paediatrics; 31(8): 265- 268

[13] Lamontagne, J., Engle, P.L., Zeithrin M.F. 1998, Maternal employment, child care and nutritional status of 12-18 months old children in Managua, Nikaragua, Social Science Medicine; 46(3): 23- 37

[14] Chaundhary, R. H.1984, Determinants of dietary intake and dietary adequacies for preschool children of Bangladesh, Food and nutrition bulletein; 6(4): 24- 32

[15] Charmarbagwala, R., Ranger, M., Waddington H., White, H. 2013 The Determinants Of Child Health And Nutrition: A
Meta-Analysis retrieved at Child health nutrition.pdf on 19/9/2014

[16] Islam, M.A., Rahman, M.M., Mahalanabis, D. 1994 Maternal and socioeconomic factors and the risk of severe malnutrition in a child: a case-control study, Eur J Clin Nutr. ; 48(6):416-24.

[17] Islam, M. M., Alam, M., Tariquzaman M.D., Kabir, M.A., Pervin, R. Begum, M., Khan, M.D.M.H. 2013, Predictors of the number of under-five malnourished children in Bangladesh: application of the generalized poisson regression model; BMC Public Health 2013, 13:11

[18] Cohen, N. 1981, Smoking, health and survival prospects in Bangladesh, Lancet; 16(1), 8229: pp1222- 1233 